\title{
Transdermal Nitroglycerin Versus Oral Nifedipine for Suppression of Preterm Labor
}

\author{
Nayereh Ghomian,' Seyyedeh Houra Vahedalain,' Fatemeh Tavassoli,, Seyyedeh Azam \\ Pourhoseini, ${ }^{2,}$ and Seyed Taghi Heydari ${ }^{3}$ \\ ${ }_{1}^{1}$ Department of Obstetrics and Gynecology, Emam Reza Hospital, Mashhad University of Medical Sciences, Mashahd, IR Iran \\ ${ }^{2}$ Department of Obstetrics and Gynecology, Ghaem Hospital, Mashhad University of Medical Sciences, Mashahd, IR Iran \\ ${ }^{3}$ Health Policy Research Center, Shiraz University of Medical Sciences, Shiraz, IR Iran \\ ${ }^{*}$ Corresponding Author: Seyyedeh Azam Pourhoseini, Department of Obstetrics and Gynecology, Ghaem Hospital, Mashhad University of Medical Sciences, Mashahd, IR Iran. \\ Tel: +98-517222622, Fax: +98-517222622, E-mail: pourhoseinia@mums.ac.ir
}

Received 2015 June 30; Revised 2015 September 15; Accepted 2015 October 15.

\begin{abstract}
Background: One of the most serious complications of pregnancy is preterm labor(PTL) and delivery. Further, there are different tocolytic agents available to enhance the time of delivery.

Objectives: The aim of this study was to compare the effectiveness of transdermal nitroglycerin (glyceryl trinitrate, GTN) and oral nifedipine for managing preterm labor.

Patients and Methods: This was a randomized clinical trial involving women who were admitted to our hospital with a diagnosis of PTL. Group one received transdermal GTN, whereas group two received oral nifedipine. All vital signs, fetal heart rate (FHR), contractions, dilation, and effacement, as well as gestation age at the time of delivery, have been monitored and evaluated in both groups of patients. Our main goal was the postponement of delivery so as to secure the most beneficial effect of primary corticosteroid administration for the fetus.

Results: Both groups were matched regarding age, gestational age at the time of tocolytic therapy, height of fundus, history of pregnancy, abortion, delivery, and stillbirth, primary body temperature, and systolic and diastolic blood pressure. Those who received GTN had a more prolonged delay of delivery. Also, the GTN group had infants with better one- and five-minute Apgar scores. Although both groups reported minimal side effects, tachycardia and nausea were reported more frequently in GTN patients.

Conclusions: Transdermal GTN was shown to be more effective in controlling PTL compared to oral nifedipine in terms of both maternal and neonatal effects.
\end{abstract}

Keywords: Nifedipine, Preterm Labor, Transdermal Nitroglycerin

\section{Background}

Delivery prior to a gestational age (GA) of 37 weeks occurs in 6 to $7 \%$ of all pregnancies, although this rate is 1 to $2 \%$ for deliveries prior to a GA of 32 weeks, and the overall incidence is increasing (1). One of the most important etiologies of perinatal morbidity and mortality is preterm labor (PTL), which could result in neonatal death or permanent sequela as well as additional costs to the healthcare system (2). To manage this problem, tocolytic agents have been used to reduce perinatal morbidity and mortality by delaying the time of delivery. Such a delay has several advantages, including allowing sufficient time for the optimum effect of corticosteroids on the pulmonary system of the fetus, promoting increased consultation with perinatologists and pediatricians, and facilitating the transfer of the neonate to a referral hospital or medical center equipped with a neonatal intensive care unit (NICU), relevant trained staff, and special equipment (3). Magnesium sulfate, $\beta$-adrenergic receptor agonists, prostaglandin inhibitors, calcium channel blockers, oxytocin antagonists, and nitric oxide donors are the tocolytic agents that have typically been applied to control PTL, and each of them has its own individual pros and cons in terms of maternal and fetal effects (4-6). Animal and human studies indicate that nitric oxide donors have been effective in delaying labor, with little or no maternal and/or neonatal side effects. The released nitric oxide causes smooth muscle relaxation as well as similar effects to progesterone in the suppression of uterine contractions in the utero-placental unit. It has also been shown that a reduction in the level of nitric oxide in the uterus can trigger labor and delivery.

\section{Objectives}

The aim of the present study was to assess the effectiveness of transdermal nitroglycerin (glyceryl trinitrate,

Copyright (C) 2015, Shiraz University of Medical Sciences. This is an open-access article distributed under the terms of the Creative Commons Attribution-NonCommercial 4.0 International License (http://creativecommons.org/licenses/by-nc/4.0/) which permits copy and redistribute the material just in noncommercial usages, provided the original work is properly cited. 
GTN) and oral nifedipine for the treatment of PTL, their maternal and fetal side effects, and their possible impacts on the prognosis of neonates.

\section{Patients and Methods}

\subsection{Study Population}

This prospective randomized clinical trial study was performed at Emam Reza hospital Mashhad University of Medical Sciences, Mashhad, Iran, over a one-year period from October 2013 to October 2014. All patients who were over 18-years-old and diagnosed with PTL were evaluated by experienced obstetricians for probable inclusion in the study.

The inclusion criteria were a GA of between 24 and 34 weeks and signs of early-onset delivery ( $\geq 4$ uterine contractions within 20 minutes, $\geq 1$ centimeter $(\mathrm{cm})$ of dilation, and effacement of over $80 \%$ ).

The exclusion criteria were maternal or fetal life-threatening conditions that require emergency termination, multiple pregnancy, premature rupture of membrane, fatal anomaly or intra-uterine fetal death, cervical dilation $\geq 4 \mathrm{~cm}$, any tocolytic treatment on previous days, and a positive allergy to GTN.

Complete matching of the two groups was performed regarding age, previous obstetric history (number of previous pregnancies, deliveries, abortions, and stillbirth), GA, height of fundus, temperature, and systolic (SBP) and diastolic blood pressure (DBP) at the time of admission (Table 1 ).

\subsection{Study Protocol}

Approval from the Institutional Review Board and the Ethics Committee of Mashhad University of Medical Sciences was obtained prior to the start of the study. This study has been successfully registered with the clinical trials service of the US National Institutes of Health (ClinicalTrials.gov Identifier: NCT02583633). All participants provided written informed consent.

In the interests of randomization, a nurse who was blinded to the study gave each patient in order of presentation a sealed envelope containing her admission number. This admission number was assigned as the medical profile number of the patient. A colleague of the researchers opened the envelopes and categorized the patients according to odd and even profile numbers (odd numbers $(\mathrm{n}=71)$ as the GTN group and even numbers ( $\mathrm{n}$ $=68$ ) as the nifedipine group) (Figure 1 ). In the nifedipine group, nifedipine softgel was applied, while in the GTN group, a GTN patch was applied. As the shapes of the two medicines were completely different, blinding was not performed, although those assessing the results were blinded to the group assignment.

All eligible patients were given intravenous normal saline (500 milliliters) for 30 minutes and then two doses of intramuscular betamethasone every 24 hours (12 milligrams up to two doses). Next, for the GTN group, transdermal GTN (Schwarz Pharma AG, Monheim am Rhien, Germany) was prescribed and placed on the patient's forearm. Each patch contained $37.4 \mathrm{mg}$ of glyceryl trinitrate, which was released into the blood stream (10 mg/24 hours). One hour after application of the first patch, uterine contractions were evaluated. If the contractions continued and/or any change in dilation and/or effacement was observed, a second patch was applied. Again, after one hour the contractions were assessed. In the case of subsided contractions or the presence of no change in effacement and dilation, the patch was left on for 48 hours. On the other hand, if the progression of contractions was observed and/or there was a change in effacement and/ or dilation, the patch was removed and another tocolytic was prescribed to stop the contractions.

For the nifedipine group, nifedipine $5 \mathrm{mg}$ softgel (Daana Pharma Co., Tabriz, Iran) was prescribed. In this group, the order of medicine prescription was:

1) One soft gel every 20 minutes ( 4 doses).

2) Two soft gel every 6 hours ( 4 doses).

3) One soft gel every 6 hours (4 doses).

4) One soft gel every 8 hours (3 doses).

Similar to the GTN group, the uterine contractions were checked every hour, and if the contractions did not subside or if there was any change in dilation and/or effacement, the treatment was stopped and another tocolytic was applied.

For both groups, the fetal heart rate (FHR) was monitored continuously during the first four hours and then it was checked periodically. Also, the blood pressure of all patients was checked every $15 \mathrm{~min}$ for the first hour and then every four hours.

The gestational age at the time of delivery and the number of women in whom contractions were stopped after four hours of treatment were compared between the two groups. Also, the duration of NICU stay, infant birth weight, Apgar scores of minute one and minute five, and incidence of neonatal respiratory distress syndrome (RDS), patent ductus arteriosus (PDA), and necrotizing enterocolitis (NEC) were documented and assessed. The maternal adverse effects of the two medicines, including hypotension, headache, tachycardia, nausea, and dermal erythema, were compared between the two groups.

\subsection{Statistical Analysis}

All data analyses were performed using Statistical Package for the Social Sciences version 16 (SPSS Inc., Chicago, Illinois, USA). Chi-squared or Fisher's exact tests were used to compare the qualitative variables between the two groups, while independent t-tests were used for the parametric variables. All data are reported as mean \pm standard deviation (SD) or proportions, as appropriate. A two-tailed P value of less than 0.05 was considered statistically significant. 


\section{Results}

Finally, data concerning 139 patients were registered and 112 patients were analyzed. No significant differences between the groups were found with regard to aspects such as age, gestational age at the beginning of study based on ultrasonography, previous obstetric history (number of previous pregnancies, deliveries, abortions, and stillbirth), height of fundus at the time of admission, baseline temperature, and baseline SBP and DBP (Table 1).

The suppression of contractions 48 hours after starting medication was significantly more common in the GTN group than in the nifedipine group $(44.64 \%$ ( $n=$ $25 / 56)$ vs $n=10, P=0.002$ ). In addition, the delivery of women treated with GTN was more prolonged in comparison to those treated with nifedipine ( 34 - 6 vs $33-5$, $\mathrm{P}=0.012)$, and their babies also had significantly higher Apgar scores of minute one and minute five (7.6 \pm 0.88 vs $7.0 \pm 0.71, \mathrm{P}=0.001$ and $8.3 \pm 1.05$ vs $7.6 \pm 1.12, \mathrm{P}=0.001$, respectively) (Table 2 ).

Table 3 depicts the maternal side effects of the drugs applied in the two groups. Although the occurrence of headache was equal in both groups, tachycardia and nausea were significantly more common in the GTN group (both tachycardia and nausea; $\mathrm{n}=5 ; 8.92 \%$ vs $\mathrm{n}=0, \mathrm{P}=$ 0.019). A local or systemic skin reaction (erythema) was not detected in any patient in either group.

Table 1. Demographic and Medical Characteristics of the GTN Group and the Nifedipine Group ${ }^{\text {a }}$

\begin{tabular}{lccc}
\hline & GTN Group $(\mathbf{n}=\mathbf{5 6})$ & Nifedipine Group $(\mathbf{n}=\mathbf{5 6})$ & P Value $^{\text {b }}$ \\
\hline Age, $\mathbf{y}$ & $27.4 \pm 3.23$ & $26.7 \pm 3.46$ & .274 \\
\hline Number of previous pregnancies & $1.8 \pm 0.81$ & $1.7 \pm 0.93$ & .517 \\
\hline Number of previous deliveries & $0.6 \pm 0.78$ & $0.4 \pm 0.68$ & .123 \\
\hline Number of previous abortions & $0.2 \pm 0.39$ & $0.3 \pm 0.57$ & .177 \\
\hline Number of previous stillbirths & $0.02 \pm 0.13$ & $0.09 \pm 0.39$ & .202 \\
\hline GA based on ultrasonography, weeks-days & $31-4$ & $32-4$ & .408 \\
\hline Height of fundus, cm & $31 \pm 1.6$ & $31 \pm 1.56$ & .952 \\
\hline Baseline temperature, centigrade & $36.99 \pm 0.13$ & $36.97 \pm 0.03$ & .922 \\
\hline Baseline systolic blood pressure, $\mathbf{m m H g}$ & $108.3 \pm 5.2$ & $108.7 \pm 5.5$ & .661 \\
\hline Baseline diastolic blood pressure, $\mathbf{m m H g}$ & $69.4 \pm 5.79$ & $70.7 \pm 2.6$ & .112 \\
\hline
\end{tabular}

Abbreviations: GA, gestational age; GTN, glyceryl trinitrate.

${ }^{\mathrm{a}}$ Data are reported as the mean $\pm \mathrm{SD}$.

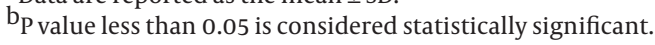

Table 2. Treatment Outcomes in the GTN Group and the Nifedipine Group ${ }^{a}$

\begin{tabular}{lccc}
\hline & GTN Group $(\mathbf{n}=\mathbf{5 6})$ & Nifedipine Group $(\mathbf{n}=\mathbf{5 6})$ & P Value $^{\mathrm{b}}$ \\
\hline GA at the Time of Delivery, weeks-days & $34-6$ & $33-5$ & 0.012 \\
Suppression of contractions after $\mathbf{4 8}$ hours & $25(44.64)$ & $10(17.86)$ & 0.002 \\
ApgarScore, minute one & $7.6 \pm 0.88$ & $7.0 \pm 0.71$ & $<0.001$ \\
ApgarScore, minute five & $8.3 \pm 1.05$ & $7.6 \pm 1.12$ & $<0.001$ \\
Infant birth weight & $2139.2 \pm 511.1$ & $2226.8 \pm 573.5$ & 0.396 \\
Duration of NICU stay & $3.4 \pm 4.69$ & $2.8 \pm 4.38$ & 0.520 \\
Neonatal RDS & $24(42.86)$ & $23(41.7)$ & 0.848 \\
Neonatal PDA & $0(0)$ & $1(0.83)$ & 0.315 \\
Neonatal NEC & $0(0)$ & $2(1.78)$ & 0.154 \\
\hline
\end{tabular}

Abbreviations: GA, gestational age; GTN, glyceryl trinitrate; NEC, necrotizing enterocolitis; NICU, neonatal intensive care unit; PDA, patent ductus arteriosus; RDS, respiratory distress syndrome.

a Data are reported as the mean \pm SD or frequency (\%) as appropriate.

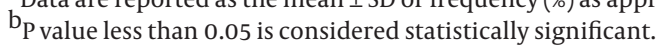


Ghomian N et al.

\begin{tabular}{lccc}
\hline Table 3. Maternal Adverse Effects in the GTN Group and the Nifedipine Group & & & \\
\hline & GTN Group $(\mathbf{n}=\mathbf{5 6})$ & Nifedipine Group (n= 56) $^{\text {a }}$ & PValue $^{\text {b }}$ \\
\hline Headache & $16(28.57)$ & $16(28.57)$ & .999 \\
Tachycardia & $5(8.92)$ & $0(0)$ & .019 \\
Nausea & $5(8.92)$ & $16(28.57)$ & .019 \\
Hypotension leading to cessation of the medication & $14(25)$ & $0(0)$ & .615 \\
Dermal erythema & $0(0)$ & .999 \\
\hline
\end{tabular}

Abbreviation: GTN, glyceryl trinitrate.

${ }^{\mathrm{a}}$ Data are reported as the frequency (\%).

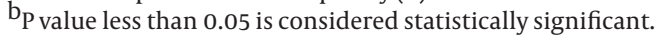

Consort Flow Diagram of the Study

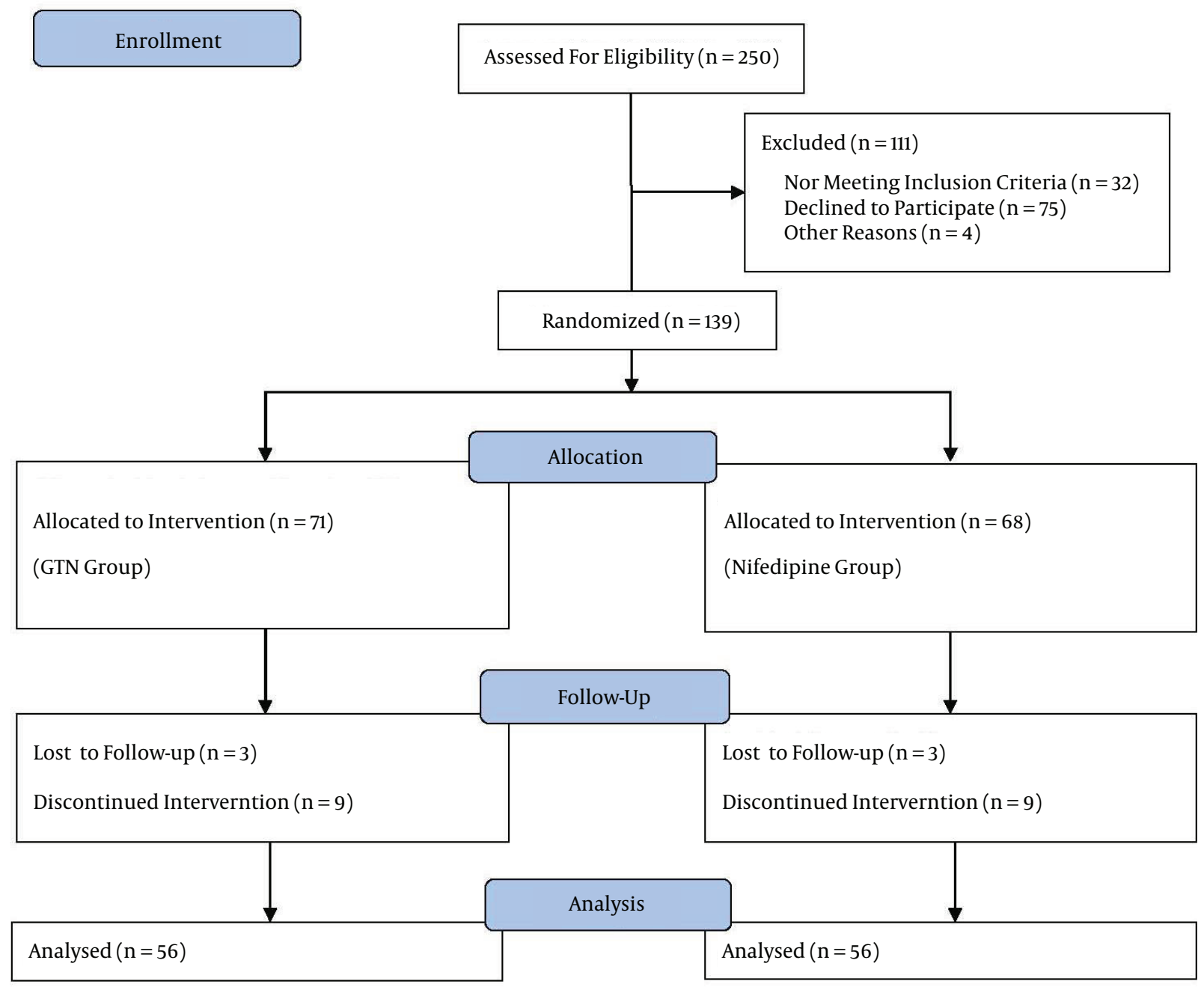

Figure 1. Flowchart of the Study Procedure 


\section{Discussion}

PTL and delivery could have devastating impacts on both the mother and the infant. Yet, management of this problem has always been a challenge for obstetricians. In this study, we compared the effectiveness of transdermal GTN and oral nifedipine for controlling PTL, and we discovered that transdermal GTN is better able to cease the uterine contractions and can thus slow the progress of delivery more efficiently.

GTN, a nitric oxide donor, has been shown to produce a significant decrease in the contractility of human myometrium in pregnant and non-pregnant women in vitro (7-10). In 1994, Lees et al. (11) reported that transdermal nitroglycerin patches suppressed uterine contractions in all 20 episodes of preterm labor that occurred in 13 consecutive women enrolled in a pilot study, and they hence suggested that this nitric oxide donor could be an effective and safe tocolytic agent.

The actual introduction of transdermal nitroglycerin for controlling preterm labor dates back to 1996, when it was beneficial in ten women (12).

In 1999, Lees et al. (13) compared the efficacy of ritodrine and GTN, and they found that there was no significant difference in acute tocolysis between these two medications; however, the overall preterm delivery rate was less in GTN patients. Also, glyceryl trinitrate had less adverse side effects. Black et al. (14) evaluated the maternal and fetal cardiovascular effects of transdermal GTN compared with ritodrine for acute tocolysis in a multicenter clinical trial involving 60 women. They reported that transdermal GTN had only trivial effects on maternal pulse rate, blood pressure, and FHR, and, therefore, it had significantly fewer adverse cardiovascular effects than intravenous ritodrine. As a consequence, transdermal GTN could be a safer and more convenient treatment option for women suffering from PTL.

In 2001, a study of 30 pregnant women of 27 to 34 weeks of GA who were diagnosed with PTL reported a decrease in uterine contractions in all women without any side effects on fetal cardiotocography and heart rate (15).

In 2010, Smith et al. (16) indicated that a reduction in overall neonatal outcome with transdermal GTN compared with a placebo was mainly due to a 23-day prolongation of pregnancy and a trend toward ending a course of corticosteroids in the subgroup randomized prior to 28 weeks' gestation. Hence, transdermal GTN could prolong the time of delivery and, therefore, reduce neonatal morbidity and mortality. Another study, which was a non-randomized clinical trial involving 65 pregnant women conducted in Pakistan, reported that transdermal GTN was an effective and safe tocolytic medication capable of prolonging the pregnancy and improving the neonatal outcome (17).

From another point of view, Guo et al. (18) performed a clinical trial on 153 pregnant women in Canada to assess the cost-effectiveness of transdermal GTN versus a place- bo. They showed that the application of transdermal GTN in the context of PTL could lessen NICU costs and significantly improve neonatal outcomes.

In a systematic review and meta-analysis published in 2013 , it was stated that compared with $\beta 2$-adrenergic receptor agonists, transdermal GTN was associated with a significant decrease in the risk of preterm birth, NICU admission, and maternal adverse effects. Nonetheless, there were no significant differences between transdermal GTN and magnesium sulfate and nifedipine in pregnancy prolongation and delivery within 48 hours of treatment, respectively (19).

In addition to the above-mentioned studies, some other surveys have been published that compared GTN to ritodrine $(14,20,21)$, magnesium sulfate $\left(\mathrm{MgSO}_{4}\right)(22)$, fenoterol magnesium sulfate (23), or salbutamol magnesium sulfate (24), as well as one case series (25).

Despite these trials showing evidence of the probable efficacy of transdermal GTN in controlling PTL, the most recent update of the Cochrane Review included randomized controlled trials involving a total of 1227 patients and declared that there was still insufficient evidence to support the routine administration of nitric oxide donors in the treatment of preterm labor (26).

Calcium channel blockers, mainly nifedipine, gained popularity as tocolytics due to the oral route of admission, the availability of immediate- and slow-release preparations, and the adequate effects on prolongation of pregnancy. However, there is growing concern regarding the overall neonatal outcome as well as the possible adverse maternal and fetal events $(27,28)$.

Nikolov et al. (29) published the results of their survey of PTL women treated with oral nifedipine in 2007. In their study, 32 out of 37 women completed their pregnancy uneventfully and, consequently, they suggested oral nifedipine as a rational alternative to other tocolytics. In a similar study in 2010, it was indicated that nifedipine was an effective, economical, and safe drug for tocolysis, and that it might be used as a substitute for $\beta$-adrenergic receptor agonists in countries with limited resources (30). The findings of this study were in accordance with our findings with regard to the effects of nifedipine in pregnancy prolongation as well as babies with lower Apgar scores. In contrast to these studies, Lyell et al.'s (31) prospective, randomized, double-blind multicenter study involving 71 pregnant women with PTL showed a different outcome. They indicated that the maintenance of nifedipine as a tocolytic medication did not result in a significant improvement in neonatal outcomes or an acceptable decrease in preterm delivery.

The results of our study showed that the application of transdermal GTN was not only efficient as a tocolytic agent due to the suppression of contractions $(\mathrm{P}=0.002)$, but it was also effective in improving GA at the time of delivery and the resultant prolonged pregnancy $(\mathrm{P}=$ 0.012). This time interval is noteworthy in relation to the 
administration and effectiveness of corticosteroids, and the statistically significant Apgar scores of minute one and minute five have been compatible with this result (P $<0.001$ for both scores).

In the present study, the most common complication was headache and its incidence was equal in both groups. Five patients in the GTN group complained of nausea after administration of the patch, and this was the same rate for tachycardia in this group $(P=0.019)$. Despite the fact that these adverse effects were significant from a statistical point of view, we detected only trivial discomfort in our patients in the clinical setting.

We noted some limitations to our study. First, due to the unavailability of placebo patches of the same size and shape as the transdermal GTN, we were unable to arrange double blinding. However, the research colleagues who conducted the statistical analysis and data interpretation were unaware of the groups. Second, on hospital admission we registered and documented the GA of pregnant women based on the ultrasonography reports of various ultrasonographists that the patient has brought with them. As our hospital is the tertiary referral center in the county, it was not feasible to provide ultrasonography for all patients by the same ultrasonographist.

In summary, the potential effectiveness, economic aspects, trivial side effects, and simplicity of administration have led obstetricians to consider and evaluate transdermal GTN in clinical decision making. Hence, conducting further randomized, double-blind, placebocontrolled clinical trials to explore the possible shortterm and long-term neonatal outcomes are highly recommended. These findings would be more practical in cases of very premature neonates for whom the prolongation of pregnancy is much more crucial to reducing the likelihood of lifelong disabilities.

\section{Acknowledgments}

The authors wish to thank all of the nursing and medical staff at Emam Reza hospital, Mashhad University of Medical Sciences, Mashhad, Iran, for their kind cooperation.

\section{Footnotes}

Authors' Contribution:Study concept and design, Nayereh Ghomian; acquisition of data, Seyyedeh Azam Pourhoseini, Seyyedeh Houra Vahedalain, Fatemeh Tavassoli; analysis and interpretation of data, Seyed Taghi Heydari; drafting of the manuscript, Nayereh Ghomian and Seyyedeh Azam Pourhoseini; critical revision of the manuscript for important intellectual content, Seyyedeh Houra Vahedalain, Fatemeh Tavassoli, Seyed Taghi Heydari; Statistical analysis, Seyed Taghi Heydari; administrative, technical, and material support, Seyyedeh Azam Pourhoseini; study supervision: Nayereh Ghomian.

Funding/Support:This project was financially supported by the Vice Chancellor for Research Affairs, Mashhad University of Medical Sciences, Mashhad, Iran.

\section{References}

1. Committee on Practice Bulletins-Obstetrics TACOO, Gynecologists. Practice bulletin no. 130: prediction and prevention of preterm birth. Obstet Gynecol. 2012;120(4):964-73. doi: 10.1097| AOG.0b013e3182723b1b. [PubMed: 22996126]

2. Petrou S. Economic consequences of preterm birth and low birthweight. BJOG. 2003;110 Suppl 20:17-23. [PubMed:12763106]

3. Smith GN. What are the realistic expectations of tocolytics? BJOG. 2003;110 Suppl 20:103-6. [PubMed:12763123]

4. Benedetti T]. Maternal complications of parenteral beta-sympathomimetic therapy for premature labor. Am J Obstet Gynecol. 1983;145(1):1-6. [PubMed: 6849333]

5. Elliott JP. Magnesium sulfate as a tocolytic agent. Am J Obstet Gynecol. 1983;147(3):277-84. [PubMed: 6624792]

6. Jennings RW, MacGillivray TE, Harrison MR. Nitric oxide inhibits preterm labor in the rhesus monkey. J Maternal-Fetal Neonata Med.1993;2(4):170-5. doi:10.3109/14767059309017336.

7. Buhimschi I, Yallampalli C, Dong YL, Garfield RE. Involvement of a nitric oxide-cyclic guanosine monophosphate pathway in control of human uterine contractility during pregnancy. Am J Obstet Gynecol.1995;172(5):1577-84. [PubMed: 7755075]

8. Norman JE, Ward LM, Martin W, Cameron AD, McGrath JC, Greer IA, et al. Effects of cGMP and the nitric oxide donors glyceryl trinitrate and sodium nitroprusside on contractions in vitro of isolated myometrial tissue from pregnant women. J Reprod Fertil. 1997;110(2):249-54. [PubMed: 9306978]

9. David M, Hamann C, Chen FC, Bruch L, Lichtenegger W. Comparison of the relaxation effect in vitro of nitroglycerin vs. fenoterol on human myometrial strips. J Perinat Med. 2000;28(3):232-42. doi:10.1515/JPM.2000.032. [PubMed:10923308]

10. Wetzka B, Schäfer WR, Stehmans A, Zahradnik HP. Effects of nitric oxide donors on the contractility and prostaglandin synthesis of myometrial strips from pregnant and non-pregnant women. $G y$ necol endocrinol. 2001;15(1):34-42. [PubMed: 11293922]

11. Lees C, Campbell S, Jauniaux E, Brown R, Ramsay B, Gibb D, et al Arrest of preterm labour and prolongation of gestation with glyceryl trinitrate, a nitric oxide donor. Lancet. 1994;343(8909):13256. [PubMed: 7910325]

12. Rowlands S, Trudinger B, Visva-Lingam S. Treatment of preterm cervical dilatation with glyceryl trinitrate, a nitric oxide donor Aust N Z J Obstet Gynaecol. 1996;36(4):377-81. [PubMed: 9006815]

13. Lees CC, Lojacono A, Thompson C, Danti L, Black RS, Tanzi P, et al Glyceryl trinitrate and ritodrine in tocolysis: an international multicenter randomized study. GTN Preterm Labour Investigation Group. Obstet Gynecol. 1999;94(3):403-8. [PubMed:10472868

14. Black RS, Lees C, Thompson C, Pickles A, Campbell S. Maternal and fetal cardiovascular effects of transdermal glyceryl trinitrate and intravenous ritodrine. Obstet Gynecol.1999;94(4):572-6. [PubMed:10511361]

15. Leszczynska-Gorzelak B, Laskowska M, Marciniak B, Oleszczuk J. Nitric oxide for treatment of threatened preterm labor. Int J Gynaecol Obstet. 2001;73(3):201-6. [PubMed:11376665]

16. Smith GN, Guo Y, Wen SW, Walker MC, Canadian Preterm Labor Nitroglycerin Trial G. Secondary analysis of the use of transdermal nitroglycerin for preterm labor. Am J Obstet Gynecol. 2010;203(6):565 e1-6. doi: 10.1016/j.ajog.2010.07.018. [PubMed 20817132]

17. Shaikh S, Shaikh AH, Akhter S, Isran B. Efficacy of transdermal nitroglycerine in idiopathic pre-term labour. J Pak Med Assoc 2012;62(1):47-50. [PubMed: 22352102]

18. Guo Y, Longo CJ, Xie R, Wen SW, Walker MC, Smith GN. Costeffectiveness of transdermal nitroglycerin use for preterm labor. Value Health. 2011;14(2):240-6. doi: 10.1016/j.jval.2010.10.019. [PubMed: 21296600]

19. Conde-Agudelo A, Romero R. Transdermal nitroglycerin for the treatment of preterm labor: a systematic review and metaanalysis. Am J Obstet Gynecol. 2013;209(6):551 e1-551 e18. doi: 10.1016/j. ajog.2013.07.022. [PubMed: 23891631]

20. Bisits A, Madsen G, Knox M, Gill A, Smith R, Yeo G, et al. The Randomized Nitric Oxide Tocolysis Trial (RNOTT) for the treatment of preterm labor. Am J Obstet Gynecol. 2004;191(3):683-90. doi: 10.1016/j.ajog.2004.02.019. [PubMed:15467526] 
21. Wani MP, Barakzai N, Graham I. Glyceryl trinitrate vs. ritodrine for the treatment of preterm labor. Int J Gynaecol Obstet.2004;85(2):1657. doi:10.1016/j.ijgo.2003.09.001. [PubMed:15099781]

22. El-Sayed YY, Riley ET, Holbrook RH, Cohen SE, Chitkara U, Druzin ML. Randomized comparison of intravenous nitroglycerin and magnesium sulfate for treatment of preterm labor. Obstet Gynecol.1999;93(1):79-83. [PubMed: 9916961]

23. Schleussner E, Moller A, Gross W, Kahler C, Moller U, Richter S, et al. Maternal and fetal side effects of tocolysis using transdermal nitroglycerin or intravenous fenoterol combined with magnesium sulfate. Eur J Obstet Gynecol Reprod Biol. 2003;106(1):14-9. [PubMed: 12475575]

24. He Q, Sha J, Gu Q, Gu H, Chen X, Yang Z, et al. [Clinical effect and mechanism of nitroglycerin patch on arresting preterm labor]. Zhonghua Fu Chan Ke Za Zhi. 2002;37(3):134-5. [PubMed:11953077]

25. de Spirlet M, Treluyer JM, Chevret S, Rey E, Tournaire M, Cabrol D, et al. Tocolytic effects of intravenous nitroglycerin. Fundam Clin Pharmacol.2004;18(2):207-13. doi:10.1111/j.1472-8206.2003.00231.x. [PubMed: 15066136]

26. Duckitt K, Thornton S, O'Donovan OP, Dowswell T. Nitric oxide donors for treating preterm labour. Cochrane Database Syst Rev. 2014;5:CD002860. doi: 10.1002/14651858.CD002860.pub2. [PubMed: 24809331]

27. Oei SG. Calcium channel blockers for tocolysis: a review of their role and safety following reports of serious adverse events. Eur J Obstet Gynecol Reprod Biol. 2006;126(2):137-45. doi: 10.1016/j. ejogrb.2006.03.001. [PubMed:16567033]

28. Nassar AH, Aoun I, Usta IM. Calcium channel blockers for the management of preterm birth: a review. Am J Perinatol. 2011;28(1):57-66. doi:10.1055/s-0 030-1262512. [PubMed: 20640972]

29. Nikolov A, Markov D, Dimitrov A, Ivanov S, Diavolov V. [Treatment of preterm delivery with calcium channel blockers--Nifedipine]. Akush Ginekol (Sofiia). 2007;46(9):18-22. [PubMed: 18642559]

30. Sy T, Diallo FB, Diallo Y, Camara MK, Diallo A, Cissoko M, et al. [Management of pre-term labor: use of nifedipine in Conakry, Guinea]. Med Trop (Mars). 2010;70(2):141-4. [PubMed: 20486348]

31. Lyell DJ, Pullen KM, Mannan J, Chitkara U, Druzin ML, Caughey AB, et al. Maintenance nifedipine tocolysis compared with placebo: a randomized controlled trial. Obstet Gynecol. 2008;112(6):1221-6. doi:10.1097/AOG.0b013e31818d8386. [PubMed:19037029] 